\title{
DISCUSSION
}

\section{Peribulbar Anesthesia for Blepharoplasty}

\author{
James H. Carraway
}

Received: 21 March 2007/Accepted: 31 March 2007

(C) Springer Science+Business Media, LLC 2007

The authors have a large experience with peribulbar anesthesia for inferior blepharoplasty. They have used it in the management of 788 patients over 9 years. Because this type of anesthesia has been used for both extraocular muscle surgery and orbital surgery, it has mostly fallen within the purview of ophthalmic and oculoplastic surgeons. It can be useful for creating anesthesia of the whole lower eyelid area, eliminating any pain that may occur from removing some of the deeper fat pockets.

Additionally, local anesthesia used in the skin and postseptal fat areas results in some distortion, which some surgeons find distracting. The incidence of hematoma with skin infiltration into the local wound is $3 \%$ to $5 \%$. This condition usually is not severe. The incidence of hematoma with the retrobulbar injection is low, but when it does occur, it can be very disturbing. However, the incidence of hematoma in the authors' series was less than $1 \%$.

I believe peribulbar anesthesia can be used successfully to explore blowout fractures of the orbital floor and for minor bony procedures along the orbital rim area. In conjunction with local infiltration, it is a good anesthetic technique for lower lid blepharoplasty, eliminating the need for direct injection into the fat pads.

Peribulbar anesthesia involves a technique that needs to be taught by someone skilled in performing it. This offers the best possible technical enlightenment for the surgeon just beginning to perform this particular procedure. This is a good article, making us aware of additional techniques that can be added to our armamentarium. 